\title{
A constituição de sentidos na oralidade e na escrita: a autoria na produção infantil
}

\author{
Pamela Aline Tizzioto \\ USP
}

\author{
Soraya Maria Romano Pacífico \\ USP
}

\author{
Lucília Maria Sousa Romão \\ USP
}

\begin{abstract}
Resumo
Na Educação Infantil, a autoria não é trabalhada, pois a função-autor não é atribuída aos textos orais, somente aos escritos. Diante disso, objetivamos demonstrar que a autoria se faz presente tanto na produção de textos orais quanto na produção de textos escritos. Fundamentamo-nos na Análise do Discurso (AD) francesa e nas teorias do letramento; os sujeitos da pesquisa são crianças da última etapa da Educação Infantil, de uma Escola Municipal, de Ribeirão Preto (SP), autores dos textos que constituem o corpus deste trabalho. A metodologia sustentase na leitura de literatura infantil, junto aos alunos; posteriormente, houve discussão e análise das marcas linguísticas presentes na interpretação oral e escrita dos textos construídos pelos sujeitos. As análises nos mostraram que, se a interpretação e produção textual dos alunos, oral e escrita, for considerada, as atividades de linguagem tornam-se significativas e possibilitam o desenvolvimento da linguagem e a assunção da autoria.
\end{abstract}

Palavras-chave: discurso, autoria, letramento, escrita.

\begin{abstract}
In early childhood education, authorship is not studied, because the author function is not assigned to oral texts, only to written ones. In view of this, we aim to demonstrate that authorship is present in oral and written texts. In this study based on French Discourse Analysis (DA) and theories of literacy, the subjects are children in the last stage of early childhood education in a municipal school of Ribeirão Preto (SP), and they are the authors of the texts that constitute the corpus of this work. The methodology uses the reading of children's literature, with students, and, following this, a discussion and analysis of the linguistic signals in the oral and written interpretation of texts constructed by the subjects. The analysis showed us that if the oral and written interpretation and production of the students are considered, the language activities become meaningful and enable the students to develop language and assume authorship.
\end{abstract}

Keywords: discourse, authorship, literacy, writing. 


\section{INTRODUÇÃO}

"O resto era o modo como pouco a pouco eu havia me transformado na pessoa que tem o meu nome. E acabei sendo o meu nome." (Clarice Lispector)

O fragmento de Clarice nos dá pistas de como o processo de nomeação e constituição do sujeito passa pela linguagem de modo sempre singular, o que para nós deveria ter relação com o ensino nas primeiras séries da vida escolar, com a aprendizagem da língua oral e escrita, com a autoria. Supomos que assumir um nome como próprio, tomando para si a responsabilidade pelo dizer (e por dizê-lo) deveria ser um dos objetivos centrais das séries em que as crianças passam a reconhecer nomes, grafá-los, marcá-los na voz e no papel, processo este que consideramos ser lento e elaborado pouco a pouco, produzindo efeitos de transformação e implicação nos sujeitos. Por isso, consideramos que a Educação Infantil é o período escolar que exerce grande influência na alfabetização de uma criança e temos desenvolvido estágios realizados em instituições de ensino procurando observar as práticas que os docentes utilizam para o desenvolvimento da alfabetização e do letramento e, também, se eles(as) permitem aos seus alunos o acesso à autoria. A escuta e a observação desse processo têm nos levado a considerar que as produções orais são muito desvalorizadas diante das produções escritas, ou seja, que há um efeito de descaso com a oralidade no ambiente escolar, onde prevalecem as atividades de cópia (Coracini, 1999), de leituras parafrásticas (Orlandi, 1996; Pacífico, 2002).

Nesse contexto, a autoria é quase inexistente, pois na escola predomina a concepção de modelo autônomo de letramento (Street, 1984; 1993), o qual concebe a escrita como superior, isto é, atribui-se uma supremacia cognitiva à escrita; sendo assim, a autoria não é atribuída aos textos orais, somente aos escritos. Diante de tais considerações, surgiu a necessidade deste trabalho que, defendendo o modelo ideológico do letramento (Street, idem), tem como objetivo demonstrar que a autoria se faz presente tanto nas produções orais quanto nos textos escritos e que há uma enorme relação entre estas duas modalidades.

Muitos teóricos do letramento têm defendido a posição que assumimos aqui, por exemplo, Tfouni, (1995, 2001), Rojo (2001), Signorini (2001), entre outros. Pode-se, então, inferir que a língua oral é tão importante quanto a escrita, e que as duas são necessárias para o desenvolvimento do aluno e para sua participação nas práticas sociais. É a partir dessa ideia que este trabalho se inicia, adicionando-se à opinião de que o processo de desenvolvimento 
começa no período em que a criança se encontra na Educação Infantil. É nesta fase que a criança necessita receber estímulos para desenvolver ainda mais a fala; surge também nesse ponto o desenvolvimento da escrita, pois é quando ela percebe que não só pode falar, como também pode escrever, ou seja, há a descoberta da existência das letras, das sílabas, das palavras, dos textos, orais e/ou escritos.

Pelas teorias do letramento, aqui relembrando as autoras acima mencionadas, temos que o sujeito pode ocupar a posição de autor mesmo sem saber sobre o escrito, ou seja, mesmo sem ser/estar alfabetizado. Isso nos leva a sustentar que crianças da Educação Infantil podem ocupar o lugar de autor, mesmo antes de sua alfabetização, visto que durante nossa experiência como estagiárias observamos marcas de autoria nas produções orais das crianças da Educação Infantil. Por ser assim, nosso trabalho fundamenta-se, teoricamente, na Análise do Discurso (AD) francesa e nas teorias do letramento.

Segundo a AD, sujeito e sentido constroem-se junto com o texto; logo, o sentido não está pronto, predeterminado (Pêcheux, 1993) como defendem as teorias positivistas. Além disso, esta teoria sustenta que as condições de produção do discurso, a saber, a circunstância de enunciação, a relação dos interlocutores, o lugar social que ocupam, interferem na construção dos sentidos. Para nós, isso é fundamental, pois pretendemos investigar em que condições de produção as crianças fazem circular seu dizer, sendo ele oral ou escrito. Uma discussão sobre Análise do Discurso (AD) exige estudo e conhecimento de alguns conceitos que constituem a base das investigações sobre o discurso. Inicialmente, precisamos entender que a $\mathrm{AD}$ visa a compreender o sujeito e seu discurso inseridos em um contexto sóciohistórico-ideológico, pois toda palavra pronunciada por um sujeito é perpassada por aspectos sociais e ideológicos (Pêcheux, 1995).

A partir desta ideia, entendemos que sujeitos ocupando posições sociais diferentes usam a língua de acordo com estas posições, ou seja, uma mesma palavra pode ser empregada e entendida de forma diferente por cada sujeito. Como o discurso, os sentidos e significados são produzidos por meio do contexto sócio-histórico em que o sujeito está inserido; pode-se dizer que o discurso não é estático, isto é, ele acompanha as transformações sociais e, por isso, pode ser classificado como uma prática de linguagem que sempre está em movimento, ou melhor, não é fixa. Conforme Orlandi (2003, p.30), as condições de produção do discurso “compreendem fundamentalmente os sujeitos e a situação. Também a memória faz parte da produção do discurso.” Assim, podemos dizer que o discurso é constituído por diferentes vozes ou dizeres, pois o sujeito produz sentidos utilizando discursos que já circula(ra)m na sociedade em que está inserido e, muitas vezes, ao mudar de uma posição discursiva a outra, 
lança mão de estratégias do discurso da oralidade ou da escrita (Gallo, 1992) conforme a relação dos interlocutores envolvidos no processo discursivo.

Assim, o discurso não apresenta um sentido único, pois o sujeito é heterogêneo, interpelado pela ideologia; ele não é o centro do seu dizer (Pêcheux, 1995). Ou seja, é pelas práticas sociais e discursos que circulam no grupo social em que vive que o sujeito produz sentidos. Então, temos que sujeito e discurso são constituídos pela ideologia. Por ser assim, o sujeito possui a ilusão de que a ele pertencem o controle dos sentidos e a origem do seu dizer, aquilo que Pêcheux (1995, p. 158, 173) nomeia como “esquecimento $n^{0} 1$ ”; isto é um equívoco, já que nos discursos estão embutidos outros e os sentidos são produzidos a partir da posição social ocupada por cada sujeito. Dessa forma, podemos dizer que a construção dos sentidos não depende da vontade do sujeito, mas sim, da relação que a língua estabelece com a história, a divisão de classes e a ideologia.

Outro ponto importante para a $\mathrm{AD}$ é o fato de o sujeito encontrar-se inserido em uma dada formação discursiva. É esta formação que, de certa forma, define o que será dito e como o será, pois como Fernandes afirma (2005, p. 60), "Formação Discursiva refere-se ao que se pode dizer somente em determinada época e espaço social, ao que tem lugar e realização a partir de condições de produção específicas, historicamente definidas”. O interior de uma formação discursiva é marcado por vários discursos ou, para utilizar a terminologia da $\mathrm{AD}$, um interdiscurso. É isto que possibilita um enunciado tornar-se outro. Isso nos leva a compreender o que é ideologia e qual a sua influência sobre a linguagem quando a estamos estudando na perspectiva discursiva. Segundo Fernandes (2005, p.29), ideologia é "uma concepção de mundo de determinado grupo social em uma circunstância histórica. Linguagem e ideologia são vinculadas; esta materializa-se naquela. Ideologia é inerente ao signo em geral.” Conforme a $\mathrm{AD}$, a ideologia é um mecanismo de naturalização dos sentidos, o que provoca um efeito de evidência dos discursos, como se o sentido só pudesse ser um, isto é, aquele determinado pela formação discursiva dominante, em dado momento histórico.

Para este trabalho, daremos destaque à formação discursiva dominante que sustenta a superioridade da escrita sobre a oralidade. Entretanto, traremos para a discussão as teorias do letramento (Tfouni, 1995; 2001; Rojo, 2001; Signorini, 2001) que defendem a importância da oralidade, criticando a teoria da grande divisa, segundo a qual há uma separação radical entre os usos orais e os usos escritos da língua, sendo estes superiores. Essa concepção leva a dizeres que defendem a presença da autoria somente em textos escritos, o que faz crer que o princípio de autoria não se faz presente nos textos produzidos oralmente (Tfouni, idem). 
Ressaltamos que nosso trabalho é justamente baseado na contraposição dessas ideias e, por isso, faz-se necessário citar o modelo ideológico de letramento (Street, 1984; 1993), o qual marca a importância da oralidade, procurando valorizar as características orais e escritas e não as diferenças de cada modalidade. Isto significa que este modelo concebe a fala e a escrita como interdependentes e relevantes para as práticas do letramento.

Analisando a realidade escolar em nosso país e estudos que têm como objeto de trabalho a produção textual em sala de aula (Coracini, 1999; 2007; Pacífico, 2002; 2007; Romão e Pacífico, 2006), pode-se chegar à conclusão de que a produção textual na forma escrita é valorizada de tal modo que, na maioria das vezes, a produção oral é totalmente escamoteada. Ou, em outras palavras, acredita-se que o aluno somente ocupe a posição de autor na produção de textos escritos (Tfouni, 1995; 2001), o que está de acordo com o discurso pedagógico do tipo autoritário (Orlandi, 1996) que circula em grande parte das instituições escolares.

Refletir sobre alfabetização e letramento, para nós, neste trabalho, significa pensar nas condições em que o sujeito, inserido na primeira etapa da vida escolar, entra em contato com a linguagem escrita; significa investigar como o código escrito chega ao contexto escolar e como ele é adquirido pelo sujeito que freqüenta essas séries escolares. Nossa investigação, então, consiste em observar a relação que o sujeito tem com a produção textual e a autoria, tanto em textos orais quanto em escritos. Melhor dizendo, observar os movimentos do sujeito para assumir o seu dizer, tomando o nome em que pouco a pouco o sujeito vai se transformar.

\section{COPISTAS OU AUTORES? UMA ANÁLISE DISCURSIVA DE ATIVIDADES DE ESCRITA EM SALA DE AULA}

\footnotetext{
"Eu não me impunha um papel mas me organizara para ser compreendida por mim, não suportaria não me encontrar no catálogo. Minha pergunta, se havia, não era: 'que sou', mas 'entre quais eu sou'."- Clarice Lispector
}

Partimos da observação do que é chamado por alguns sujeitos-professores de "escrita espontânea", que consiste em a criança praticar seu conhecimento sobre a escrita, a partir de desenhos. Estas atividades são muito utilizadas na escola e teriam por objetivo motivar o aluno a escrever o nome das ilustrações sozinho, sem copiar. Como analistas de discurso, estranhamos o uso dessa expressão, “escrita espontânea”, pois a nosso ver as práticas de 
leitura e escrita no contexto escolar não se sustentam na espontaneidade, o que cria um efeito de livre escolha e surgimento de algo sem esforço ou empenho.

Também acreditamos que, para ser "espontânea” a escrita deveria ser uma atividade de escolha da criança, ou seja, esta deveria ter a liberdade de escrever o que e sobre o que quisesse, “espontaneamente”, possibilidade interditada quando uma lista de desenhos é mostrada à criança e a ela cabe fazer a transposição de um sistema semiótico (visual) a outro (verbal). Temos reservas quanto ao fato de uma criança, ao escrever "árvore” ao lado da figura de um pirulito ou "macaco" ao lado de um coelho, conforme veremos abaixo, ter a aprovação de uma professora, partindo do princípio de que essa seja uma atividade de "escrita espontânea”. A partir do momento que o sentido já está dado, predeterminado pela linguagem visual, a escrita deixa de ser espontânea.

Criticando essa concepção de sentido único, a $\mathrm{AD}$ defende que sujeito e sentidos constroem-se junto com o texto, em cada atividade de linguagem. Por isso, os sentidos não são únicos, nem transparentes, pois sempre podem tornar-se outros. As atividades desenvolvidas pelas professoras das turmas são divididas em dois modelos. No primeiro, a criança deve apenas copiar o desenho da lousa e colocar o nome da figura ao lado do desenho; no outro, as figuras já se encontram na folha (carimbadas ou desenhadas) e, ao lado, há uma linha para que o aluno escreva o nome da figura. O problema é que este tipo de exercício não estimula o aluno a criar novos textos, a ocupar outras posições, a assumir-se em seu nome, ou seja, a autoria não é trabalhada quando o aluno se encontra limitado a escrever apenas palavras soltas, descontextualizadas; além disso, as palavras não são por ele escolhidas. Então, o que ocorre é que o sujeito-criança é levado a fazer o que é pedido por sua professora, que direcionou a relação do aluno com a linguagem.

Consideramos pertinente observar que nossa experiência no contexto escolar permitenos dizer que o aluno, nesta instituição, durante todos os anos escolares, precisa "provar” sua competência para leitura e escrita, de acordo com a chamada língua culta ou padrão (modalidade escrita, por excelência), mesmo que ele não use, “essencialmente”, tal variante em suas práticas sociais, em que predomina a variante coloquial ou popular (modalidade oral). Talvez este seja o ponto crucial que faz com que os alunos “odeiem” escrever, fazer redações, pois, muitas vezes, a escola lhes coloca um abismo separando aquilo que eles conhecem sobre o uso da língua e aquilo que essa instituição espera que seja feito. Isso pode ser constatado inúmeras vezes quando, diante da proposta de um tema para redação, os alunos dizem que "sabem falar, mas não sabem como escrever”, ou ainda, “saber, eu sei, mas não sei como escrever". 
Entendemos que as dificuldades devem ter início no período escolar que estamos investigando, em que os professores apresentam a escrita como um jogo de adivinhação, que logo nas séries posteriores se transforma em um jogo de acertos e erros, no qual o "erro" sempre é punido e os acertos, logicamente, premiados. Isso acaba silenciando o dizer de muitos alunos (cf. Pacífico, 2002), os quais, com medo de errar, passam pelos anos escolares apenas copiando da lousa, dos colegas, do professor. Como observamos, a atividade proposta solicita da criança uma produção escrita descontextualizada; parece que o objetivo é que a criança exercite a grafia das letras, como se fosse importante verificar quais letras as crianças conhecem e quais não, e se elas podem/sabem colocar o traçado das letras numa linearidade, formando palavras que não têm relação entre si. Sabemos que falamos por textos e não por palavras isoladas. Não cumprimentamos alguém dizendo: bombom, dia, borboleta, casa, macaco, etc. Sequer vamos ao supermercado e pedimos: uva, vovô, unha, maçã, ou navio.

Defendemos que seria mais interessante trabalhar com portadores de texto que circundam a sociedade, desde as placas de trânsito até as embalagens dos produtos que invadem nossas casas. Dessa forma, a criança aprenderia a ler palavras inseridas em determinado contexto, que têm uma função social que não simplesmente a realização de uma atividade escolar. Nas atividades que se seguem, observamos que há possibilidade da produção de um texto, já que uma receita (sopa) é um texto, não apenas palavras isoladas. A produção de uma receita culinária exige uma amarração, um começo, meio e fim, coesos e coerentes para que o prato seja bem-elaborado.

A nosso ver, a professora poderia ter aproveitado a oportunidade para trabalhar a produção textual, construir com a sala um caderno de receitas, um cardápio para o inverno, considerando o tipo de alimento que é a sopa, ou seja, criar situações em que a escrita seja usada de modo significativo. No entanto, o que temos, novamente, é a escrita de palavras isoladas, dos nomes de legumes que devem fazer parte da sopa e não da receita da sopa, conforme podemos constatar nas produções que se seguem:
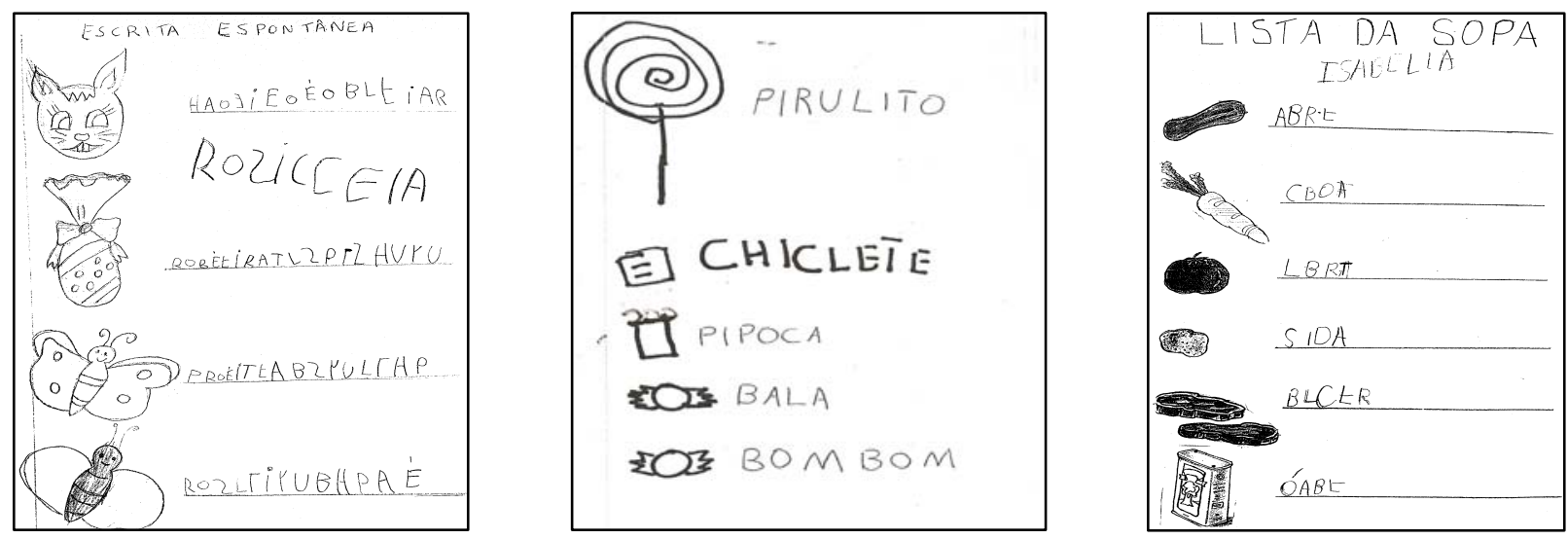
Observamos, nos dados acima, como a escrita ainda não é apresentada de modo significativo para a criança, a qual grafa seu nome, “Isabella”, logo abaixo da "lista da sopa”, criando um efeito de sentido em que seu nome também poderia fazer parte da lista. O mesmo pode ser observado com o nome "Rosicléia”, que aparece solto, junto aos nomes dos desenhos que ela deveria registrar. Marcamos aqui um retorno ao fragmento de Clarice Lispector colocado na primeira epígrafe, ressaltando o modo como esse sujeito toma o seu nome assumindo-o no desenho, inscrevendo-o na lista, tomando-o como seu. A nosso ver, a professora deveria ter deixado um espaço, no cabeçalho, para a escrita do nome, com a presença da palavra “NOME” e um traço na frente, onde a criança escreveria seu nome, como fazemos inúmeras vezes cotidianamente ao preenchermos formulários, requerimentos e tantos outros veículos que exigem nossa identificação. Com isso, o nome "Isabella” não estaria “jogado” na folha, junto à “abóbora”, “cenoura” etc e, além disso, a professora iniciaria seus alunos na escrita de documentos que fazem parte do nosso dia a dia, ou seja, a atividade poderia ajudar as crianças a se familiarizarem com textos que circulam na sociedade, tais como formulários, fichas, cadastros, entre outros que exigem a escrita do nome, no cabeçalho.

\section{AUTORIA: UM MODO DE DIZER SOBRE AS ATIVIDADES DE ESCRITA EM SALA DE AULA \\ “(...) sou-me inalcançável como me é inalcançável um astro.”- Clarice Lispector}

Indo numa direção oposta às atividades realizadas pelas professoras, no trabalho com a linguagem que propusemos durante a pesquisa os alunos eram estimulados a não se prenderem somente à narrativa do livro discutido; ao contrário, deveriam utilizá-la como base para uma nova história. Segundo Pêcheux (1995, p. 167), "pode-se bem dizer que o intradiscurso, enquanto "fio do discurso" do sujeito, é, a rigor, um efeito do interdiscurso sobre si mesmo, uma "interioridade” inteiramente determinada como tal "do exterior”."

Buscando relacionar interdiscurso e intradiscurso, nosso objetivo era possibilitar que as crianças criassem novos textos e, para isso, elas precisavam sentir-se seguras para colocar em prática todo o seu conhecimento sobre escrita. Por este motivo, a oralidade era muito bem trabalhada antes da escrita, a fim de que os alunos percebessem que poderiam, sozinhos, produzir novas histórias. Com base nesse entendimento, adotamos a seguinte metodologia.

A atividade foi realizada com duas classes diferentes. Num primeiro momento, as crianças eram convidadas a escutar a leitura de um livro. Durante essa atividade, os alunos eram estimulados a dialogar sobre o livro e seus sentidos. Perguntas sobre o vocabulário, 
sobre as ilustrações e sobre o que elas achavam da história eram feitas durante toda a leitura. Após isso, os alunos eram convidados a criarem, oralmente, novas histórias. Ao terminarem as histórias orais, cada criança deveria sentar-se em seu lugar de costume e passar para o papel sua história. Para a realização da atividade escrita, as crianças contavam com seu próprio conhecimento sobre o código escrito, com os coleguinhas e com o alfabeto exposto na sala.

Com esta atividade pudemos perceber que os alunos, em sua maioria, mostravam dificuldades para produzirem histórias novas, tanto na forma oral quanto na escrita. A dificuldade maior era no momento de escrever, pois as crianças não estavam acostumadas com atividades de escrita em que deveriam construir histórias; mostravam-se, por outro lado, muito familiarizadas com exercícios de cópia, tanto que, em vários momentos, a frase “Tia, passa na lousa” era colocada em discurso. Além disso, uma parte dos alunos parecia ter medo de errar já que, a cada palavra que tentavam escrever, faziam a pergunta “Tá certo?”. Muitos apenas copiavam o alfabeto ou algo que já estava escrito, na lousa, independentemente de a palavra ter, ou não, relação com o texto lido.

Percebemos, também, que as professoras desta escola não tinham o hábito de utilizar como metodologia de alfabetização atividades em que os alunos deveriam criar textos, pois para elas, como os alunos ainda não eram alfabetizados, eles não conseguiriam produzir textos. Entre estas professoras, as atividades baseadas na cópia eram as mais utilizadas, além disso, quando os alunos eram convidados a escrever durante as aulas, a atividade consistia apenas em colocar o nome da figura que se encontrava desenhada na folha de exercício, como já analisamos. Outra constatação que fizemos foi que os alunos apenas realizavam as atividades da maneira como a professora pedia e não conseguiam ocupar o lugar de autor, pois não criavam nada sem antes perguntar o que deveriam fazer. Isto nos indica que as crianças não tinham o hábito de produzir nada que não fosse copiado da lousa ou pedido pela professora o que, como já apontamos, sempre é baseado em cópias, em leituras parafrásticas (Orlandi, 1996) que não permitem o posicionamento dos alunos perante um objeto discursivo. Sendo assim, quando as crianças são solicitadas a produzirem algo, recorrem à professora, que detém, imaginariamente, um saber. Também, segundo os pressupostos da AD, pelo efeito da ideologia, o professor ocupa um lugar de quem tem um saber legitimado que ditará o que pode e deve ser dito, escrito, desenhado, em sala de aula.

Passemos às produções orais, que constituem um ponto central do nosso trabalho, já que, como estamos defendendo, grau de escolaridade não tem relação direta com grau de letramento e a autoria está relacionada a grau de letramento e não de escolaridade. Durante a 
pesquisa, muitos alunos não se mostravam seguros para criarem histórias de natureza alguma, nem oral e muito menos escrita. Por esse motivo, a quantidade de produções orais que temos é pequena, mas muito valiosa para nosso trabalho, visto que, com estas histórias poderemos mostrar aquilo que estamos defendendo, ou seja, mesmo não sendo alfabetizadas, estas crianças, sujeitos de nossa pesquisa, com condições favoráveis à produção textual, conseguem, sim, ocupar a posição de autor. Após a leitura, os alunos deveriam elaborar novas histórias com base no livro lido e discutido. Lemos, com os alunos sempre em sala de aula, devido ao espaço físico da escola que não oferecia muitas possibilidades de locais para a leitura. Os alunos ficavam próximos ao livro, sentados no chão, junto à professora, a fim de se envolverem mais na trama que estava sendo tecida pela/na narrativa lida. Abaixo, temos um exemplo de uma narrativa oral (transcrita por nós) produzida após a atividade de leitura da obra UUUUUUU Um Barulho Estranho, de Liliana Iacocca.

\section{Sujeito: G (5 anos)}

\section{Narrativa: O ouro de cristal}

O ouro de cristal, ele vivia jogado no chão. Um dia a bruxa apareceu e pegou ele. A bruxa escondeu ele... aí a princesa abriu o buraco e achou ele e pegou ele...aí a bruxa foi pegar o ouro e ele não estava mais lá. Um dia a rainha falou para a princesa: Que ouro bonito!!! E viveram felizes pra sempre.

Observamos que a criança realizou uma leitura polissêmica, pois não copiou os sentidos do texto lido, mas escreveu sobre bruxas, princesa, rainha, elementos presentes nos contos de fadas, o que indica que o sujeito que construiu esse texto tem uma identificação maior com os contos do que com a narrativa lida. Percebemos que o sujeito tem um conhecimento sobre os contos de fadas, porque constrói um enredo parecido com aqueles que sustentam os contos tradicionais e termina com “e viveram felizes para sempre.”

Nesta narrativa, a função autor foi ocupada pela criança, já que o texto apresenta determinada coesão e coerência, pois, mesmo com a ausência de alguns mecanismos de coesão, o sujeito conseguiu dar coerência ao texto. Além disso, ele demonstrou conhecimento sobre tempo verbal e concordância (vivia jogado; apareceu e pegou; escondeu, abriu, achou e pegou; não estava) narrando toda a história em tempo passado. A frase "e viveram felizes para sempre” é usada para encerrar o texto, como o fechamento dos contos de fada. A produção seguinte deu-se a partir da leitura do texto O jumentinho guloso, de Márcia Coivo Villela. 


\section{Sujeito: A. (5 anos)}

\section{Narrativa: O cachorro}

Eu tinha um cachorro... aí ele comeu carne e morreu.

Eu fiquei com saudade.

Podemos dizer que o sujeito elegeu para sua produção um sentido trabalhado no texto lido, a saber, a comida; daí a presença do significante "guloso” no título da obra. Porém, o sujeito não escreveu sobre um jumento que comia de tudo, mas sim, sobre um “cachorro" que talvez não fosse guloso, contudo, morreu depois de ter comido carne. Em poucas linhas, o aluno conseguiu dar um fechamento coerente para sua escrita ao expor seu sentimento em relação à perda do seu animal. Não há dispersão de sentidos, o que mostra a capacidade do aluno em ocupar a posição de autor, mesmo na oralidade.

A narrativa abaixo foi produzida após a leitura da obra Tô cheio de ser um hipopótamo, de Pierre Cornuel. O texto trata de um hipopótamo que não queria ter essa vida e passa a imitar outros animais, deseja ser outro animal. Para essa produção, precisamos fazer uma intervenção mais pontual, pois nesse dia a sala estava lotada e o grande número de alunos favorecia a dispersão da classe; por isso, fez-se necessário um direcionamento do trabalho, a fim de que os alunos construíssem sentidos coerentes para seus textos. Vejamos a narrativa do sujeito.

\section{Sujeito: I. (6 anos)}

\section{Narrativa: Era uma vez uma menina}

C: - Era uma vez uma menina que queria se chamar Gabriely...

P: - Por que ela queria se chamar Gabriely?

C: - Porque ela era muito safada...

P: - Por que safada?

C: - Porque ela não obedecia à mãe dela...

P: - E o que mais aconteceu com esta menina?

C: - Ela bateu na cabeça do amigo...

P: - Ela bateu no amigo, mas o problema não é que queria ter outro nome?

C: - Daí ela mudou o nome para Beatriz... aí depois ela não queria mais chamar Beatriz...

P: - E aí o que aconteceu? Ela queria se chamar Beatriz?

C: - Aí ela queria se chamar Bel...

P: - Bel?

C: - É e depois ela mudou o nome para Cigana...

P: - Por que cigana?

C: - Porque a mãe dela falou que ela tinha um pai cigano e falou pra ela ter o nome de Cigana...

P: - E o que ela fez para mudar o nome de Beatriz para Cigana?

C: - Mas aí ela queria se chamar Cigana...

P: - Mas o que ela fez para mudar de nome? Você ainda não me falou.

C: - Aí ela pegou e mudou o nome pra Stefani... 
P: - E o que ela fez pra mudar o nome pra Stefani? Ela pensou: "vou me chamar Stefani” e pronto? Ela não contou pra ninguém?

C: - Não...

P: - Mas assim todo mundo ia continuar chamando a menina de Beatriz não ia?

C: - É, mas aí ela começou a falar pra todo mundo que ela queria chamar Stefani... e todo mundo começou chamar ela de Stefani...

P: - E aí? Essa história não tem fim?

C: - Depois disso ela enjoou do nome Stefani e inventou outro nome..

P: - Que outro nome?

C: - Rosicléia... E aí ela mudou o nome pra Rosicléia e fim.

Nesta narrativa, a criança precisou de ajuda para conduzir seu texto, pois em alguns momentos a dispersão e a deriva dos sentidos aparecem, como pode ser constatado no recorte: “Ela bateu no amigo, mas o problema não é que queria ter outro nome?”. Como vimos, nossa fala tentou controlar a deriva e fazer com que o sujeito voltasse aos sentidos que estavam em jogo, ou seja, a procura da menina por um outro nome. Por esse motivo, julgamos relevante ajudar o sujeito a controlar os sentidos do seu texto, a fim de não fugir do tema em que estava trabalhando. Observamos que a insatisfação do hipopótamo é discutida pelo sujeito com relação à insatisfação da menina com seu nome. Por um deslizamento de sentidos, o sujeito passa da leitura da obra para a posição de autor, historicizando os sentidos, uma vez que muitas crianças não gostam de seus nomes e desejam trocá-los. Ocorre, então, que não há uma repetição do texto lido, mas sim, uma nova produção textual, o que é fundamental para que o princípio de autoria se instale. Interessante notar que o nome que fecha a narrativa é de uma coleguinha de classe, "Rosicléia”, como já lido anteriormente. Observamos que o lugar de autor foi ocupado pelos sujeitos desta pesquisa, com muito mais propriedade, nas produções orais, o que não nos causa estranhamento. O que estranhamos, sim, é o fato de a escola não considerar a produção oral dos alunos, desvalorizando-as em relação à escrita, a qual, como vimos, está voltada para o ensino da grafia de palavras, e não para a produção de textos.

Como podemos ver nos exemplos expostos abaixo sobre o tema “Aniversário”, as crianças - acreditamos ter sido assim por ser a primeira vez que deveriam criar textos - não produziram uma nova história com o tema discutido, apenas tentaram escrever o nome dos itens que podem ser encontrados em uma festa de aniversário. Este tipo de escrita é compatível com o que os alunos estavam acostumados a fazer em sala de aula, já que a maior parte das atividades, dadas pela professora da turma, consistia apenas em cópia e em nomear figuras. Como era o primeiro encontro de nossa intervenção, as crianças não foram instigadas a escrever um texto. 

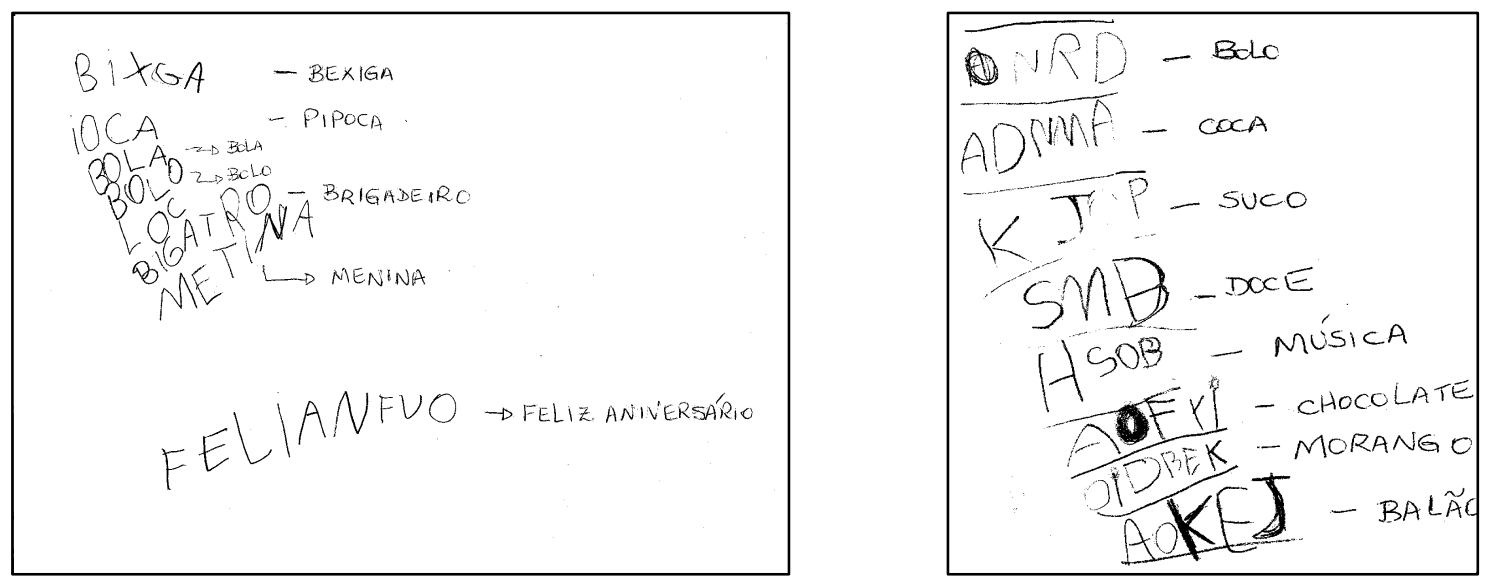

Mesmo assim, percebemos que os alunos se mostraram apreensivos no início da atividade, mas ao final pareciam estar mais confortáveis com o exercício. Apesar de os alunos terem escrito palavras isoladas, pois estão acostumados a essa prática pedagógica, como já citado, entendemos que houve uma produção que está es(ins)crita no campo semântico da festa de aniversário, já que os sujeitos escreveram palavras que são relacionadas com o tema escolhido. Isso porque os nomes relacionados ao tema evocaram diferentes redes de memória, permitiram a emergência da polissemia e a assunção de autores em diferentes posições, embora alguns significantes tenham sido regularizados nas listas acima.

\section{CONSIDERAÇÕES FINAIS}

"Dá-me a tua mão desconhecida, que a vida está me doendo, e não sei como falar - a realidade é delicada de mãos, só a realidade é delicada, minha irrealidade $e$ minha imaginação são mais pesadas." - Clarice Lispector

Ao longo deste trabalho de pesquisa defendemos a ideia de que linguagem oral e linguagem escrita são importantes para o desenvolvimento do sujeito. Para tal defesa, utilizamos como base os estudos e concepções das teorias do letramento e da Análise do Discurso (AD) de linha francesa. Para estas teorias as duas formas de linguagem verbal são relevantes para o desenvolvimento do sujeito, já que estas modalidades circulam na sociedade. Além disso, defendemos que a autoria, termo este tão destacado por nós durante todo o trabalho, deve e precisa ser trabalhada em sala de aula, mesmo que os alunos ainda não sejam ou estejam alfabetizados e que um sujeito pode ocupar o lugar de autor tanto em textos orais quanto em textos escritos. 
A criança desenvolve a sua linguagem, oral ou escrita, de acordo com a sociedade em que está inserida, ou seja, as práticas sociais de seu grupo de convívio são por ela apreendidas e estas influenciam suas práticas de leitura e escrita. Isto é, o letramento é um processo sóciohistórico, que nos dá a possibilidade de dizer que a aquisição da linguagem, escrita ou oral, é impregnada pelas práticas sociais. É através do conceito de letramento que conseguimos sustentar que a aprendizagem da linguagem escrita não deve ser trabalhada somente como codificação e a leitura não deve apenas ser classificada como decodificação do código escrito. Por este motivo, a escola durante o ensino da linguagem não pode deixar de levar em consideração que a criança já possui um conhecimento prévio sobre esta, conhecimento este que provém das práticas sociais de leitura e escrita de sua comunidade.

As teorias da $\mathrm{AD}$ e do letramento podem contribuir para que o professor trabalhe com seus alunos a produção textual de uma forma diferenciada, pois por meio destes estudos o profissional da educação consegue perceber que a utilização de diferentes tipos e gêneros de textos em sala de aula pode contribuir para que seus alunos ampliem as possibilidades de interpretações e entendimento sobre o texto. Desta forma, trabalhar o desenvolvimento da autoria se torna muito mais viável, mesmo na Educação Infantil, modalidade de ensino esta que é responsável pelo atendimento a crianças ainda não alfabetizadas. Ou seja, metodologias que têm como base o modelo autônomo de letramento (Street, 1993), o qual coloca a escrita como superior à oralidade, e utilizam atividades voltadas para a cópia e leituras parafrásticas, não estimulam o aluno a desenvolver o seu papel de autor, somente fazem com que estes repitam o discurso que já está presente no texto, ou no ambiente escolar. O aluno fica preso a uma única interpretação, a um único sentido; logo, fica interditada a leitura polissêmica dos textos, a qual dá abertura para variadas possibilidades de interpretação. É o que ocorria durante as atividades desenvolvidas pelas professoras da escola-campo, já que estas eram voltadas para a cópia e leituras parafrásticas, pois, ao ler um livro para as crianças, as professoras não dialogavam com os alunos sobre os possíveis sentidos para aquela história, apenas liam o livro. Como já dito anteriormente, as professoras das turmas cujos alunos foram sujeitos desta pesquisa não acreditavam na capacidade das crianças de produzirem um texto, pois estas ainda não estavam alfabetizadas. A oralidade também era pouco trabalhada, como também já foi citado em outros momentos deste trabalho; a alfabetização, ou melhor, a aquisição do código escrito era o objetivo principal destas professoras. Todas as práticas destas docentes não estimulavam os alunos a produzirem textos e o trabalho com a autoria não era objeto de reflexão destas profissionais. Estas práticas levam as crianças a não produzirem textos e a não se colocarem na posição de autores, como vimos nas produções de 
alguns alunos durante este trabalho de pesquisa, já que eles apenas faziam cópia de letras, palavras ou frases escritas e expostas em algum lugar da sala de aula.

Isso foi o que comprovamos com as produções infantis apresentadas neste trabalho. No início, o trabalho de produção textual foi difícil, mas, aos poucos, as crianças se mostraram mais confiantes e provaram-nos que realmente são capazes de ocupar a posição de autores, em textos orais ou em textos escritos. Em outras palavras, a produção de textos na Educação Infantil precisa começar a ser vista de outra forma; é pela produção de textos, orais ou escritos, que o professor tem maneiras de avaliar o grau de conhecimento e compreensão da linguagem de cada aluno, assim como, observar como cada um usa a língua para constituir-se como sujeito de/na linguagem. Se todo professor levasse em consideração a capacidade de interpretação e produção textual de seus alunos, tanto oral quanto escrita, as atividades de linguagem seriam mais significativas e mostrariam melhores resultados no que se refere ao desenvolvimento da língua escrita e à assunção da autoria. Para isso, os fundamentos da $\mathrm{AD}$ e das teorias do letramento podem ser usados para sustentar o trabalho em sala de aula, independentemente da faixa etária dos alunos, pois o ponto fundamental é que a oralidade, a leitura e a escrita permitam ao sujeito construir sentidos, ocupar o lugar de autor e inserir-se em suas práticas sociais. Só assim, julgamos ser possível discursivizar o nome de um sujeito, sua historicidade e seus movimentos de sentidos, sempre plurais.

\section{REFERÊNCIAS}

Coracini, M. J. (org.) (1999). Interpretação, autoria e legitimação do livro didático. Campinas-SP: Pontes.

. (2007) "Nossa língua: materna ou madrasta: linguagem, discurso e identidade”. In: . A celebração do Outro: arquivo, memória e identidade. Campinas-SP: Mercado das

Letras, p. 135-148.

Fernandes, C. A. (2005). Linguística - análise do discurso: reflexões introdutórias. Goiânia GO: Trilhas Urbanas.

Gallo, S. L. (1992). Discurso da escrita e ensino. Campinas, SP: Editora da UNICAMP.

Orlandi, E. P. (1996). A linguagem e seu funcionamento: as formas do discurso. CampinasSP: Pontes.

. (2003). Análise de Discurso: princípios e procedimentos. 5ed. Campinas-SP: Pontes.

Pacífico, S. M. R. (2002). Argumentação e autoria: o silenciamento do dizer. Tese de Doutorado inédita. Faculdade de Filosofia, Ciências e Letras de Ribeirão Preto/USP. 
(2007). “O silêncio do/no livro didático”. In: Pacífico, S. M. R.; Romão, L. M. S. Leitura e Escrita: no caminho das linguagens. Ribeirão Preto-SP: Editora Alphabeto, p. 1324.

Pêcheux, M. (1993). Por uma análise automática do discurso: uma introdução a obra de Michel Pêcheux. In: Gadet, F \& Hak, T.(org.). Campinas, SP: Editora da UNICAMP.

. (1995). Semântica e discurso: uma crítica à afirmação do óbvio. Tradução de Eni Pulcinelli Orlandi [et al]. 2ed. Campinas, SP: Editora da UNICAMP.

Rojo, R. (2001). "Letramento escolar, oralidade e escrita em sala de aula: diferentes modalidades ou gêneros do discurso?” In: SIGNORINI, I. (org.) Investigando a relação oral/escrito e as teorias do letramento. Campinas-SP: Mercado das Letras.

Romão, L. M. S.; Pacífico, S. M. R. (2006). Era uma vez, uma outra historia: leitura e interpretação na sala de aula. São Paulo: DCL.

Signorini, I. (org.). (2001). Investigando a relação oral/escrito e as teorias do letramento. Campinas-SP: Mercado das Letras.

Street, B. (1984). Literacy in theory and practice. Cambridge: Cambridge University Press.

. (1993). "Introduction: the new literacy studies". In: (ed.) Cross-cultural approaches to literacy. Cambridge: Cambridge University Press, p. 1-21.

Tfouni, L. V. (1995). Letramento e alfabetização. São Paulo: Cortez.

. (2001). “A dispersão e a deriva na constituição da autoria e suas implicações para uma teoria do letramento”. In: SIGNORINI, I. (org.) Investigando a relação oral/escrito e as teorias do letramento. Campinas-SP: Mercado das Letras.

\section{AS AUTORAS}

Pamela Aline Tizioto é pedagoga formada pela FFCLRP/USP. Aprovada, em novembro de 2009, para iniciar Pós-Graduação, em nível de Mestrado, junto ao Programa de PósGraduação em Psicologia, na FFCLRP/USP. Contato: (16) 39796243 / pamela.tizioto@hotmail.com.

Soraya Maria Romano Pacífico é doutora em Psicologia e Educação pela Universidade de São Paulo (FFCLRP-USP). Docente dos cursos de graduação em Pedagogia e Pós-Graduação em Psicologia da FFCLRP/USP. Coordenadora do Grupo de pesquisa "Memória e discurso: os movimentos do sujeito", cadastrado junto ao Diretório de grupos do CNPQ. Pesquisadora em Análise do Discurso de orientação francesa, com diversos livros publicados sobre o tema. Contato: (16) 32511786 / smrpacifico@ffclrp.usp.

Lucília Maria Sousa Romão é doutora em Psicologia e Educação pela Universidade de São Paulo (FFCLRP-USP). Docente dos cursos de graduação em 
Ciências da Informação e da Documentação e do Programa de Pós-Graduação em Psicologia da FFCLRP/USP. Professora colaboradora do Programa de Mestrado em Ciência, Tecnologia e Sociedade da UFSCar. Bolsista CNPQ. Coordenadora do Grupo de pesquisa "Memória e discurso: os movimentos do sujeito", cadastrado junto ao Diretório de grupos do CNPQ. Pesquisadora em Análise do Discurso de orientação francesa, com diversos livros publicados sobre o tema. Contato: (16) 36231875 / luciliamsr@uol.com.br. 